\title{
Accuracy of Contact Lens Method by Spherical and Aspheric Rigid Gas Permeable Lenses on Corneal Power Determination in Normal Eyes
}

(Ketepatan Kaedah Kanta Sentuh dengan Kanta Sfera dan Asferik Gas Tegar Boleh Telap ke atas Penentuan Daya Kornea pada Mata Normal)

\author{
Md Muziman Syah Md Mustafa*, Haliza Abdul Mutalib, Noorhazayti Ab. Halim \& Mohd Radzi Hilmi
}

\section{ABSTRACT}

Contact lens method (CLM) is an alternative option to measure corneal power by evaluating the difference of patient's over-refraction with rigid gas permeable (RGP) lens to manifest refraction. The purpose of this study was to evaluate

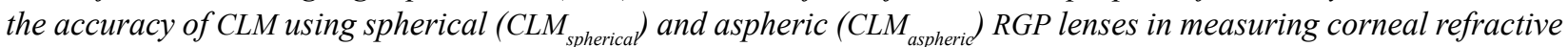
power of normal corneas. This prospective study recruited 45 normal eyes of 45 healthy subjects. The corneal power measurements were determined by CLM spherical using Boston ES RGP and CLM aspheric using Boston Envision RGP based on alignment fitting strategy. Manifest refraction and over-refraction were determined using a standard procedure of objective and subjective refraction methods. IOLMaster was set as the reference method for comparison. The mean arithmetic difference, mean absolute difference and 95\% limits of agreement (LOA) of corneal powers obtained from CLM $M_{\text {spherical }}$ and CLM aspheric to IOLMaster value were evaluated for the accuracy assessment. The mean arithmetic difference and mean absolute difference of corneal power s obtained from $C_{\text {spherical }}$ and CLM aspheric to IOLMaster values were $0.10 \pm 0.21 \mathrm{D}$ and $0.20 \pm 0.11 \mathrm{D}$, and $0.04 \pm 0.09 \mathrm{D}$ and $0.08 \pm 0.05 \mathrm{D}$, respectively. The $95 \%$ LOA between CLM spherical and IOLMaster ranged from -0.30 to $0.51 \mathrm{D}$, whereas between CLM aspheric and IOLMaster was ranging from -0.14 to $0.21 \mathrm{D}$. CLM in estimating corneal power is more accurate with application of aspheric RGP compared to spherical RGP. Hence, aspheric RGP is suggested for CLM when determining corneal power in normal eyes.

Keywords: Aspheric RGP; contact lens design; contact lens method; corneal power; rigid gas permeable

\section{ABSTRAK}

Kaedah kantah sentuh (CLM) merupakan satu pilihan alternatif untuk menentukan kuasa kornea dengan menilai perbezaan atas-pembiasan dengan kanta sentuh separa keras (RGP) kepada refraksi nyata. Tujuan kajian ini adalah untuk menilai ketepatan CLM menggunakan kanta sentuh sfera (CLM ${ }_{\text {spherical }}$ ) dan asferik (CLM aspheric dalam pengukuran kuasa refraksi kornea normal. Kajian prospektif ini merekrut 45 mata normal daripada 45 subjek sihat. Pengukuran kuasa kornea ditentukan oleh CLM ${ }_{\text {spherical }}$ menggunakan RGP Boston ES dan CLM ${ }_{\text {aspheric }}$ menggunakan RGP Boston Envision berdasarkan strategi pemasangan optimum. Refraksi nyata dan atas-pembiasan ditentukan menggunakan keadah refraksi objektif dan subjektif yang piawai. IOLMaster ditetapkan sebagai kaedah rujukan untuk perbandingan. Min perbezaan aritmetik, min perbezaan mutlak dan 95\% had-had persetujuan (LOA) kuasa kornea yang diperoleh daripada CLM ${ }_{\text {spherical }}$ dan CLM ${ }_{\text {aspheric }}$ kepada nilai IOLMaster dinilai untuk perbandingan ketepatan. Min perbezaan aritmetik dan min perbezaan mutlak kuasa kornea yang diperoleh CLM spherical dan $C L M_{\text {aspheric }}$ kepada nilai IOLMaster adalah masing-masing $0.10 \pm 0.21 \mathrm{D}$ dan $0.20 \pm 0.11 \mathrm{D}$ dan $0.04 \pm 0.09 \mathrm{D}$ dan 0.08 \pm 0.05 D. Julat 95\% LOA antara CLM ${ }_{\text {spherical }}$ dan IOLMaster adalah -0.30 ke 0.51 D, manakala antara CLM aspheric dan IOLMaster adalah -0.14 ke 0.21 D. CLM dalam menganggar kuasa kornea adalah lebih tepat dengan menggunakan $R G P$ asferik berbanding RGP sfera. Oleh demikian, penggunaan RGP asferik dicadangkan untuk CLM bagi menentukan kuasa kornea pada mata normal.

Kata kunci: Kaedah kanta sentuh; kanta sentuh separa keras; kuasa kornea; reka bentuk kanta sentuh; RGP asferik

\section{INTRODUCTION}

Corneal power contributes two-thirds of the total refractive power of human eye. It is an essential parameter in detecting any corneal abnormalities (Fan et al. 2018) as well as intraocular lens (IOL) power calculation in post-phacoemulsification (Choi et al. 2017). Its accuracy leads to correct diagnosis for corneal abnormalities (Fan et al. 2018) and IOL power determination (Fabian 
et al. 2019). There are various keratometry instruments to measure corneal power. In general, the measurement principle of keratometry can be categorized into several types; the use of anterior corneal surface as mirror to obtain reflective image for measurement (in a keratometer), videokeratoscopy with Placido disc (in a topographer), slit scanning elevation topography (in Orbscan), 360 degrees of rotating Scheimpflug camera (in Pentacam, Galilei), and optical coherence tomography imaging techniques (in IOLMaster, Optical Coherence Tomographer, Sirius) (Fan et al. 2018). Corneal power is routinely obtained from conventional keratometer (Dehnavi et al. 2015) based on simulated keratometry (Sim-K). Keratometer measures anterior corneal surface at $3.0 \mathrm{~mm}$ area of paracentral cornea by assuming the surface has a uniform curvature with a constant posterior/anterior corneal curvature ratio. Sim-K measurement uses a 1.3375 keratometric index to estimate the total corneal power from the anterior corneal curvature.

Contact lens method (CLM) is an alternative procedure to obtain corneal power which is normally applied in post-laser refractive correction cases in the absence of preoperative data. CLM determines the corneal power by assessing the difference of patient's over-refraction with rigid gas permeable (RGP) lens to manifest refraction. RGP trial lens set is commonly available in both optometry and ophthalmology clinics, and the fitting assessment is routinely being performed by optometrists. Thus, CLM could be a useful method especially in the absence of keratometry instrument or in rural areas where access to this instrument is limited.

Previous studies have reported that the CLM results varied in different visual acuity, media opacity levels (Zeh \& Koch 1999), selection of RGP fitting strategies and contact lens diameter sizes (Joslin et al. 2005). Several authors reported that CLM has low accuracy in determining post-laser refractive surgery corneal power (Haigis 2003; Kim et al. 2002; Taheri et al. 2009). One of the critical factors that needs to be evaluated is the lens design, which is important in achieving a good fit in contact lens assessment. Hence, it is vital to determine which commonly use RGP lens designs that can produce more accurate result for CLM. The main purpose of this work was to evaluate the accuracy of CLM using spherical $\left(\mathrm{CLM}_{\text {spherical }}\right)$ and aspheric $\left(\mathrm{CLM}_{\text {aspheric }}\right)$ RGP lenses in determining corneal power of normal eyes.

\section{MATERIALS AND METHODS}

A total of 45 eyes (45 subjects) were involved in this prospective study. Subjects were randomly selected among patients who had attended the IIUM Optometry Clinic. Those with history of ocular disease, surgery or trauma, best corrected visual acuity (BCVA) of worse than 6/9 (Zeh \& Koch 1999), refractive errors more than 4.00 DS and/or 2.00 DC or were wearing contact lens were excluded (Md Muziman Syah et al. 2016a). This study only included the dominant eye of the subjects (Armstrong 2013) which was determined using the holein-card test (Ding et al. 2018).

Prior to commencement of the study, each subject was explained in details the purposes, benefits, potential risks, and procedures related to this study. A written consent form was signed by all subjects once they understood and agreed to all the terms and conditions. This study was conducted in accordance with institutional guidelines and the tenets of the Declaration of Helsinki. Protocol of the study was approved and ethical approval was obtained from the Institutional Research Ethics Committee (Reference number: UKM 1.21.3/244/NN056-2013).

Two types of RGP lenses, namely the spherical and aspheric designs were used in this study. The spherical RGP lens used was Boston ES (Oculus (M) Sdn. Bhd., Selangor, Malaysia) with base curve (BC) of 7.00 to 8.30 $\mathrm{mm}$ in $0.10 \mathrm{~mm}$ step, diameter of $10.00 \mathrm{~mm}$ and power of -3.00 D. The aspheric RGP lens used was Boston Envision (Oculus (M) Sdn. Bhd., Selangor, Malaysia) with $\mathrm{BC}$ ranging from 7.30 to $8.30 \mathrm{~mm}$ in $0.10 \mathrm{~mm}$ step, diameter of $9.60 \mathrm{~mm}$ and power of $-3.00 \mathrm{D}$. Boston Envision has junctionless bi-aspheric back surface design and wide fitting zone.

\section{MEASUREMENTS}

A careful history taking, slit lamp biomicroscopy examination and keratometric (K) measurement by Grand Seiko WR-5100K autokeratometer (Grand Seiko Co. Ltd., Hiroshima, Japan) were performed to exclude those who did not fulfil the inclusion criteria. Grand Seiko autokeratometer was selected due to its high precision in measuring the K-reading (Davies et al. 2003; Md Muziman Syah et al. 2016b).

Once the inclusion criteria were fulfilled, the manifest refraction was determined through dry retinoscopy and subsequently subjective refraction without any contact lenses on the eye, $\mathrm{R}_{0}$. It was followed by the contact lenses fitting. The sequence of the contact lens fittings using the spherical and aspheric RGPs were performed randomly by Research Randomizer software (Urbaniak \& Plous 2016) to minimise operator bias. The initial BC selection was based on K-reading obtained from Grand Seiko autokeratometer. Subjects were asked to adapt with the inserted RGP for minimum of $15 \mathrm{~min}$ or until subjects comfortable with it. Evaluation of the lens centration, movement and fitting was performed under slit lamp biomicroscopy. The criteria of a good fit were defined as the lens must achieve good centration, 
where the superior edge of the lens should remain under the superior lid during a full cycle of each blink and moderate movement upon blinking.

The corneal-contact lens fluorescein pattern was assessed after establishing the appropriate lens centration and movement. The $\mathrm{BC}$ of the RGP was changed accordingly until alignment fit was observed, $\mathrm{C}_{\mathrm{BC}}$. The ideal fluorescein pattern should exhibit an alignment relationship, modest peripheral edge lift and no obstruction of tear flow behind the lens (Efron 2002). Once alignment fit was observed, the final overrefraction with RGP lens on the eye was obtained, $R_{C L}$, through subjective measurement following objective over-refraction.

After one week of completing the CLM evaluation, the corneal power was then measured using IOLMaster 500 (Carl Zeiss Meditec, Jena, Germany). Subjects were instructed to blink a few times and look at the fixation target with eyes opened widely. The measurements were taken while subjects maintained their focus on the target. Three readings were taken and the average corneal power reading was automatically calculated. The procedure was carried out before the corneal power by CLM was calculated to avoid measurement bias. The IOLMaster was set as the reference method for accuracy comparison because it has an excellent reliability in measuring corneal power (Md Muziman Syah et al. 2016b; Wang et al. 2012).

Results of the spherical equivalent (SE) of refraction without contact lens, $\mathrm{R}_{0}$; the contact lens $\mathrm{BC}$ of the alignment fit, $\mathrm{C}_{\mathrm{BC}}$; the power of the contact lens used, $\mathrm{C}_{\mathrm{Rx}}$; and the $\mathrm{SE}$ of over-refraction with contact lens on the eye, $R_{C L}$ were inserted to the CLM equation for corneal power determination. All the measurements were recorded in dioptre (D) and the refractions were converted at $12 \mathrm{~mm}$ corneal plane. The corneal power using CLM was calculated by (1);

$$
\mathrm{CLM}=\mathrm{C}_{\mathrm{BC}}+\mathrm{C}_{\mathrm{Rx}}+\left(\mathrm{R}_{\mathrm{CL}}-\mathrm{R}_{0}\right)
$$

All the procedures were performed by a single optometrist (M.M.S.M.M.) in the same setting throughout the study.

\section{STATISTICAL ANALYSIS}

The data were analysed using Statistical Package for the Social Sciences software version 25.0 (SPSS Inc., Chicago, Illinois, United State) and MedCalc software version 18.2.1 (MedCalc Software, Mariakerke, Belgium). Shapiro-Wilks test was employed to evaluate the normality of the data.

One-way repeated measures analysis of variance (ANOVA) with Bonferroni multiple comparisons was employed to determine the differences in the mean corneal powers between $\mathrm{CLM}_{\text {spherical }}$ and $\mathrm{CLM}_{\text {aspheric }}$ to IOLMaster values (Pan et al. 2019). The mean absolute difference was also evaluated. The significant level $(p)$ of less than 0.05 was set to define statistical significance for the comparison. The accuracy of both CLM and $\mathrm{CLM}_{\text {aspheric }}$ were evaluated by the $95 \%$ limits of agreement (LOA) to IOLMaster values (Bland \& Altman 2003, 1986; McAlinden et al. 2011). The 95\% LOA was determined by mean arithmetic difference \pm 1.96 of its standard deviation of difference. The $95 \%$ LOA of $\leq \pm 0.25 \mathrm{D}$ between the tested and reference methods was considered clinically accepted and to have high accuracy (Shneor et al. 2012).

\section{RESULTS}

Twenty-three right eyes and 22 left eyes of the 45 subjects were involved. The mean age of the subjects was $22.09 \pm 1.24$ years ranging from 20 to 25 years. The subjects consisted of 15 males $(33.3 \%)$ and 30 females $(66.7 \%)$. The range of SE of subjects' refraction was +0.50 to $-3.88 \mathrm{D}$ with the mean of $-0.98 \pm 1.25$ D. The mean corneal powers obtained by CLM spherical' $_{\text {, }}$ $\mathrm{CLM}_{\text {aspheric }}$, and IOLMaster were $43.78 \pm 0.94 \mathrm{D}, 43.84$ $\pm 0.96 \mathrm{D}$ and $43.88 \pm 0.96 \mathrm{D}$, respectively. All of the measurements met the normality assumption of ShapiroWilks test with $p>0.05$.

Both of the corneal powers obtained by CLM $_{\text {spherical' }}$, and $\mathrm{CLM}_{\text {aspheric }}$ were statistically lower than IOLMaster result by $0.10 \mathrm{D}$ and 0.04 on average, respectively $(F=7.271, p<0.05)$. However, the mean absolute difference between IOLMaster-CLM spherical $_{\text {, and been }}$ IOLMaster-CLM ${ }_{\text {aspheric }}$ values were only $0.20 \mathrm{D}$ and 0.08 $\mathrm{D}$, respectively (Table 1). The range of $95 \%$ LOA of $\mathrm{CLM}_{\text {aspheric }}$ was smaller than $95 \%$ LOA of CLM spherical $_{\text {with }}$ most of the data were found within upper and lower 95\% LOA (Table 1, Figures 1 and 2).

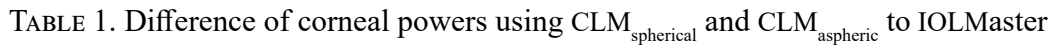

\begin{tabular}{lccccc}
\hline & \multicolumn{5}{c}{ Corneal Power (D) } \\
\cline { 2 - 5 } Methods & MD (SD) & $p^{\mathrm{a}}$ & Range & AbsMD (SD) & 95\% LOA (Range) \\
\hline CLM $_{\text {spherical }}$ & $0.10(0.21)$ & $0.004^{\mathrm{b}}$ & -0.35 to 0.50 & $0.20(0.11)$ & $-0.30 ;+0.51(0.81)$ \\
CLM $_{\text {aspheric }}$ & $0.04(0.09)$ & $0.015^{\mathrm{b}}$ & -0.12 to 0.22 & $0.08(0.05)$ & $-0.14 ;+0.21(0.35)$ \\
\hline
\end{tabular}

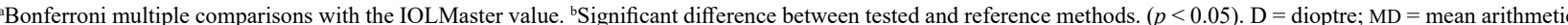
difference; AbsMD = mean absolute difference; $\mathrm{SD}$ = standard deviation; $\mathrm{LOA}=$ limits of agreement 


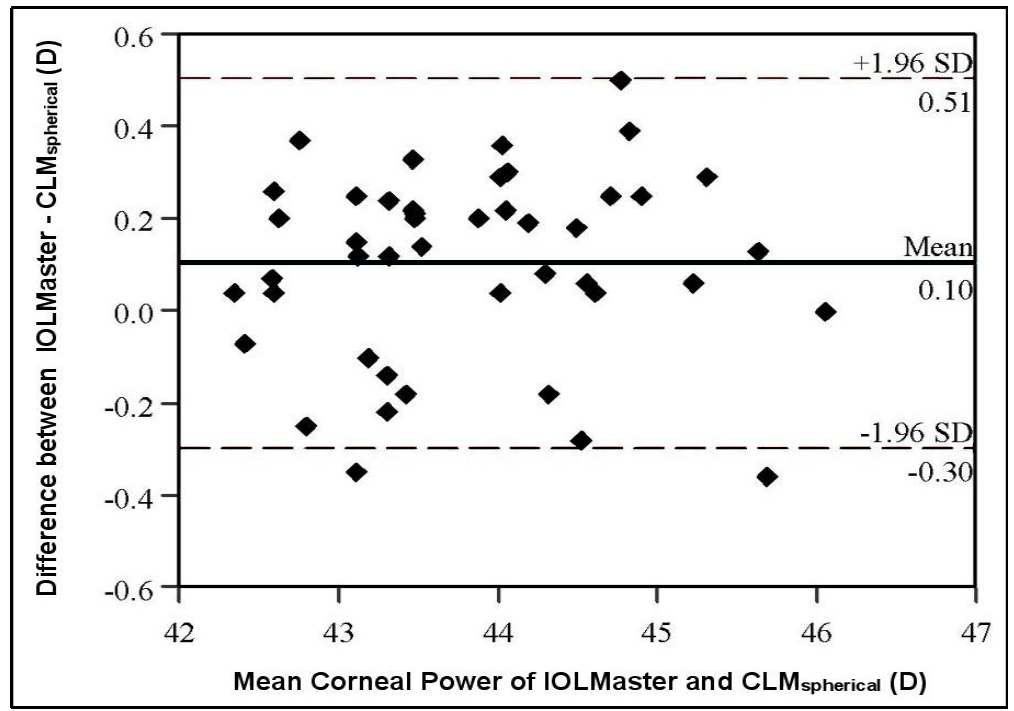

FIGURE 1. Bland-Altman plot for corneal power determination using IOLMaster and $\mathrm{CLM}_{\text {spherical }}$

Solid line is mean difference; Dashed lines are lower and upper 95\% LOA

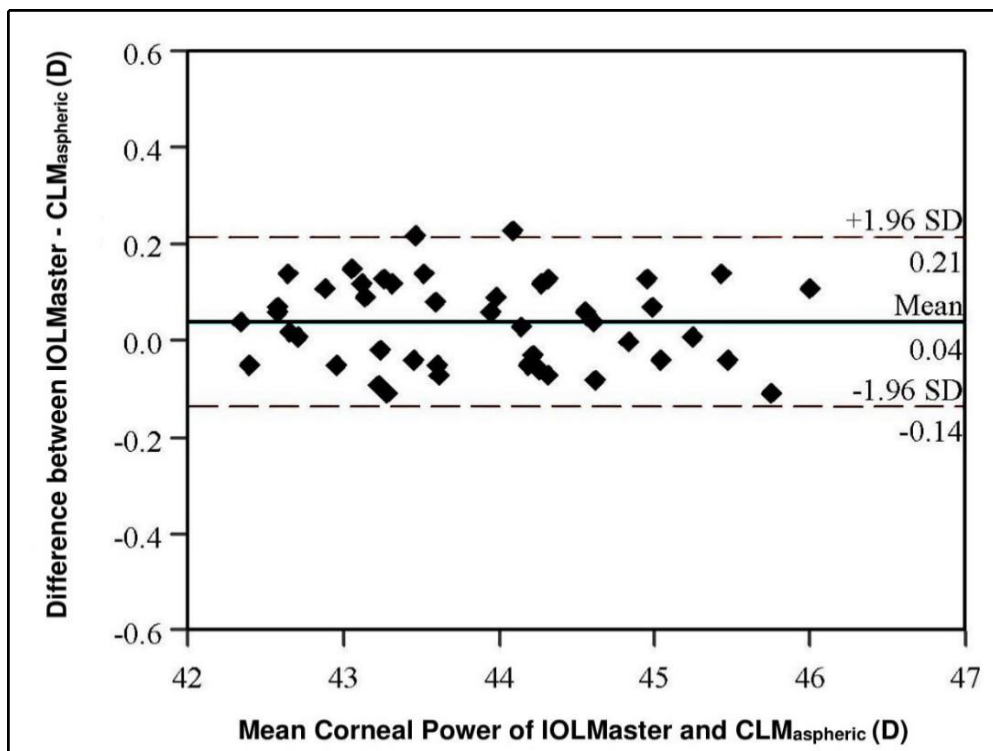

FIGURE 2. Bland-Altman plot for corneal power determination using IOLMaster and CLM

Solid line is mean difference; Dashed lines are lower and upper 95\% LOA

DISCUSSION

Contact lens method can be an alternative option to determine corneal power on normal corneas with good visual acuity (Zeh \& Koch 1999), suitable for postoperative corneas (Joslin et al. 2005) and useful in absence of keratometry instrument. From this present study, although both $\mathrm{CLM}_{\text {aspheric }}$, and $\mathrm{CLM}_{\text {spherical }}$ values were statistically less than IOLMaster values in determining central power of normal corneas, the differences showed in mean absolute differences were not clinically meaningful. These findings showed that CLM using either aspheric or spherical RGPs on alignment fitting with good lens centration on normal cornea produced higher accuracy than previous work by Zeh and Koch (1999). The previous authors used traditional spherical hard polymethyl methacrylate (PMMA) on flattest 
K-reading fitting with limited of three $\mathrm{BC}$ choices $(7.00$ $\mathrm{mm} /$ plano; $7.70 \mathrm{~mm} /+0.12 \mathrm{D} \& 8.30 \mathrm{~mm} /$ plano) in their study (Zeh \& Koch 1999). The higher accuracy could be attributed to the alignment fit and good lens centration of RGP on every subject achieved through using a wider range of $B C$ selection ( 7.00 to $8.30 \mathrm{~mm}$ in $0.10 \mathrm{~mm}$ step). It is worth to note that as the alignment fit did not create a significant lacrimal lens power, hence the $C_{B C}$ would have an almost equal to corneal curvature, and the $\mathrm{R}_{\mathrm{CL}}$ could be approximately similar to the $\mathrm{R}_{0}$. Good lens centration technique ensured the corneal power truly measured at central optic zone of RGP lens via entrance pupil which incorporates the Stiles-Crawford effect (Zeh $\&$ Koch 1999). In a case of decentred lens, the CLM assessment would be at peripheral region of RGP lens that could not represent the actual corneal power. The use of a wider range of $\mathrm{BC}$ helped the optometrist to choose a closely match BC of the RGP to the subjects' corneal curvature. This present work suggested that good lens centration with alignment fit and the use of full range of the RGP BCs does improve the accuracy of corneal power measurement using CLM in normal eyes.

The main aim of our study was to compare and evaluate the accuracy of CLM using spherical and aspheric RGP lenses in measuring corneal refractive power of normal corneas. In comparison between the two RGP lens designs used in this study, CLM aspheric $_{\text {showed }}$ a higher accuracy than CLM $_{\text {spherical }}$ with a smaller mean absolute difference and narrower 95\% LOA range. The mean absolute difference of CLM aspheric $_{\text {was almost equal }}$ to zero. The $95 \%$ LOA of CLM aspheric were approximately $\pm 0.25 \mathrm{D}$, within clinical acceptance. Whereas, the $95 \%$ LOA of CLM $M_{\text {spherical }}$ were larger than \pm 0.25 D. Previous work found that aspheric RGP (Boston Envision) had better uniform fit than spherical RGP (Schwallie et al. 1995). A contact lens with a back spherical surface design, its transition of the base curve to secondary curve may not match to the aspheric cornea surface. It creates less uniform distribution of the lens mass and exhibits more focal bearing onto the cornea. Thus, it could be postulated that the aspheric posterior surface of Boston Envision well-resembled the anterior corneal surface, which the lens design has smooth transitioned between its base curve and secondary curve. Hence, the aspheric lens design provided a uniform lens mass distribution to the entire cornea (Steele \& Davidson 2007), in which a better uniform bearing area with less focalized pressure on the corneal surface. In addition, aspheric RGP has lesser posterior sagittal depth compared to spherical RGP. This could provide more apical bearing at centre of the cornea. These characteristics further improved CLM accuracy in determining the corneal power of normal corneas.

Gullstrand's eye model study in corneal power measurement reported that the CLM value was flatter approximately $0.20 \mathrm{D}$ than the true back vertex power (Haigis 2003). In contrast, this current study showed that $\mathrm{CLM}_{\text {aspheric }}$ was only flatter by $0.08 \mathrm{D}$ on average in comparison to the reference method value. This discrepancy could be due to several factors. The current study was done on real subjects' corneas which had different parameters compared to the eye model. Based on Gullstrand's eye model, the posterior corneal curvature is $6.80 \mathrm{~mm}$, but in the human eye is about $6.50 \mathrm{~mm}$ only (Ang et al. 2014). Moreover, previous work employed paraxial geometrical optics with a thinlens assumption in calculating the CLM value (Haigis 2003) which is not truly applicable on real eyes. Thus, this finding suggested that real subject's corneas are a better approach to determine the accuracy of CLM.

Theoretically, a larger diameter RGP is expected to produce a better lens stability which could improve lens centration on the eye. However, this current study

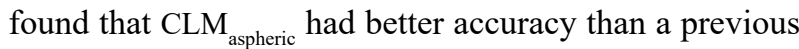
report by Joslin et al. (2005) which used a larger diameter RGP (15.00 mm versus $9.60 \mathrm{~mm})$. In this current study, the $95 \%$ LOA were only within $\pm 0.25 \mathrm{D}$. There were several possible factors that attributed to this difference. First, Joslin et al. (2005) were carried out the CLM on post-myopic LASIK corneas, where the surgically altered corneas may be multifocal. Second, number of subjects recruited was relatively small. Third, a different reference method which was the historical method has been employed. Hence, the reference method was not comparable with the current study. Fourth, the refraction was done under cycloplegic condition which might not show the physiological corneal power (Md Muziman Syah et al. 2016a; Zeh \& Koch 1999). With regards to the lens design, both studies could not be compared in details as Joslin et al. (2005) did not state the lens design used in their study. This finding suggested that the successful of RGP fitting was more dependent on the lens design rather than the lens diameter. Therefore, it could indirectly improve the accuracy of CLM.

The purpose of instillation of local anaesthetic of proparacaine (Zeh \& Koch 1999) was to improve the subjects' cooperation during the CLM assessment. However, it could deteriorate the accuracy of CLM as it alters the physiological tear reflex secretion. In RGP lens fitting, a lacrimal lens created between the posterior surface of RGP and the anterior surface of cornea would be beneficial to determine the over-refraction, indirectly the accuracy of CLM. This factor was controlled in our study by not applying any anaesthetic agent into the subjects' eyes. In respect to subjects' cooperation, the subjects were allowed to adapt with the inserted RGP for minimum of 15 min before the lens fitting and over-refraction assessments. This approach aided the subjects' comfortability towards the RGP lens and to ensure that the CLM measured a physiological corneal power.

CLM has several advantages in measuring corneal power. First, RGP trial lens set is relatively inexpensive and widely available in clinic settings. Second, in calculating the corneal power, a clinician only requires to determine the best RGP fitting, $\mathrm{C}_{\mathrm{BC}}$ to be used for the 
over-refraction power determination, $\mathrm{R}_{\mathrm{CL}}$. Third, the refraction without a RGP, $\mathrm{R}_{0}$ can be evaluated before the lens insertion, and if the CLM is performed on postoperative eye, the $\mathrm{R}_{0}$ is accessible at postoperative visit, while RGP lens power, $\mathrm{C}_{\mathrm{Rx}}$ is constant. Lastly, CLM determines corneal power through entrance pupil which incorporates the Stiles-Crawford effect and does not affected by corneal refractive index (Zeh \& Koch 1999).

It should be highlighted that there were several strengths of this current study. In order to minimise random measurement error, this study included a relatively larger sample (45 eyes) of the same group of BCVA. This present study also conducted the CLM in one eye of each subject which did not violate the independent sample (Sainani 2010). These approaches mentioned above further proved that with minimal bias, a consistent and accurate corneal power measurement can be obtained using $\mathrm{CLM}_{\text {aspheric }}$

\section{CONCLUSION}

In conclusion, higher accuracy of CLM via RGP lenses can be achieved in normal eyes by using aspheric RGP compared to spherical RGP. Therefore, the use of aspheric RGP lens for CLM as an alternative method to determine corneal power in normal eyes is recommended.

\section{ACKNOWLEDGEMENTS}

This work was supported by the International Islamic University Malaysia (grant number: RIGS 16-129-0293). Special thanks to all IIUM optometry staff for their assistance and special appreciation to all subjects who volunteered to be involved in this study.

\section{REFERENCES}

Ang, M., Chong, W., Huang, H., Wong, T.Y., He, M.G., Aung, T. \& Mehta, J.S. 2014. Determinants of posterior corneal biometric measurements in a multi-ethnic Asian population. PLoS ONE 9(7): e101483.

Armstrong, R.A. 2013. Statistical guidelines for the analysis of data obtained from one or both eyes. Ophthalmic and Physiological Optics 33(1): 7-14.

Bland, J.M. \& Altman, D.G. 2003. Applying the right statistics: Analyses of measurement studies. The Official Journal of the International Society of Ultrasound in Obstetrics and Gynecology 22(1): 85-93.

Bland, J.M. \& Altman, D.G. 1986. Statistical methods for assessing agreement between two methods of clinical measurement. The Lancet 1(8476): 307-310.

Choi, Y., Eom, Y., Song, J.S. \& Kim, H.M. 2017. Influence of corneal power on intraocular lens power of the second eye in the SRK/T formula in bilateral cataract surgery. $B M C$ Ophthalmology 17(1): 261.

Davies, L.N., Mallen, E.A.H., Wolffsohn, J.S. \& Gilmartin, B.
2003. Clinical evaluation of the Shin-Nippon NVision-K 5001/Grand Seiko WR-5100K autorefractor. Optometry and Vision Science 80(4): 320-324.

Dehnavi, Z., Khabazkhoob, M., Mirzajani, A., Jabbarvand, M., Yekta, A. \& Jafarzadehpur, E. 2015. Comparison of the corneal power measurements with the TMS4Topographer, Pentacam HR, IOL Master, and Javal Keratometer. Middle East African Journal of Ophthalmology 22(2): 233-237.

Ding, Y., Naber, M., Gayet, S., Van der Stigchel, S. \& Paffen, C.L.E. 2018. Assessing the generalizability of eye dominance across binocular rivalry, onset rivalry, and continuous flash suppression. Journal of Vision 18(6): 1-13.

Efron, N. 2002. Rigid Lens Design and Fitting: Contact Lens Practice. 1st ed. Oxford: Butterworth-Heinemann.

Fabian, E. \& Wehner, W. 2019. Prediction accuracy of total keratometry compared to standard keratometry using different intraocular lens power formulas. Journal of Refractive Surgery 35(6): 362-368.

Fan, R., Chan, T.C., Prakash, G. \& Jhanji, V. 2018. Applications of corneal topography and tomography: A review. Clinical and Experimental Ophthalmology 46(2): 133-146.

Haigis, W. 2003. Corneal power after refractive surgery for myopia: Contact lens method. Journal of Cataract and Refractive Surgery 29(7): 1397-1411.

Joslin, C.E., Koster, J. \& Tu, E.Y. 2005. Contact lens overrefraction variability in corneal power estimation after refractive surgery. Journal of Cataract and Refractive Surgery 31(12): 2287-2292.

Kim, J.H., Lee, D.H. \& Joo, C.K. 2002. Measuring corneal power for intraocular lens power calculation after refractive surgery: Comparison of methods. Journal of Cataract and Refractive Surgery 28(11): 1932-1938.

McAlinden, C., Khadka, J. \& Pesudovs, K. 2011. Statistical methods for conducting agreement (comparison of clinical tests) and precision (repeatability or reproducibility) studies in optometry and ophthalmology. Ophthalmic and Physiological Optics 31(4): 330-338.

Md Muziman Syah, M.M., Mutalib, H.A., Sharanjeet-Kaur, M.S. \& Khairidzan, M.K. 2016a. New modified equation of contact lens method in determining post myopic laser refractive surgery corneal power. The International Medical Journal Malaysia 15(1): 61-68.

Md Muziman Syah, M.M., Mutalib, H.A., Sharanjeet-Kaur, M.S. \& Khairidzan, M.K. 2016b. A comparative study on the inter-session and inter-examiner reliability of corneal power measurement using various keratometry instruments. The International Medical Journal Malaysia 15(1): 69-74.

Pan, C., Tan, W., Hua, Y. \& Lei, X. 2019. Comprehensive evaluation of total corneal refractive power by ray tracing in predicting corneal power in eyes after small incision lenticule extraction. PLOS ONE 14(6): e0217478.

Sainani, K. 2010. The importance of accounting for correlated observations. Physical Medicine and Rehabilitation 2(9): 858-861.

Schwallie, J.D., Barr, J.T. \& Carney, L.G. 1995. The effects of spherical and aspheric rigid gas permeable contact lenses: Corneal curvature and topography changes. International Contact Lens Clinic 22(3): 69-79. 
Shneor, E., Millodot, M., Zyroff, M. \& Gordon-Shaag, A. 2012. Validation of keratometric measurements obtained with a new integrated aberrometry-topography system. Journal of Optometry 5(2): 80-86.

Steele, C. \& Davidson, J. 2007. Contact lens fitting post-laserin situ keratomileusis (LASIK). Contact Lens and Anterior Eye 30(2): 84-93.

Taheri, S.M.R., Kheiltash, A. \& Hashemi, H. 2009. Comparison of corneal power and intraocular lens power calculation methods after LASIK for myopia. Iranian Journal of Ophthalmology 21(4): 45-54.

Urbaniak, G.C. \& Plous, S. 2016. Research Randomizer (Version 4.0). https://www.randomizer.org/. Accessed on 1 July 2019.

Wang, Q., Savini, G., Hoffer, K.J., Xu, Z., Feng, Y., Wen, D. \& Huang, J. 2012. A comprehensive assessment of the precision and agreement of anterior corneal power measurements obtained using 8 different devices. PLOSONE 7(9): e45607.

Zeh, W.G. \& Koch, D.D. 1999. Comparison of contact lens overrefraction and standard keratometry for measuring corneal curvature in eyes with lenticular opacity. Journal of Cataract and Refractive Surgery 25(17): 898-903.

Md Muziman Syah Md Mustafa* \& Mohd Radzi Hilmi Department of Optometry and Visual Science Kulliyyah of Allied Health Sciences International Islamic University Malaysia Bandar Indera Mahkota 25200 Kuantan, Pahang Darul Makmur Malaysia
Haliza Abdul Mutalib

Optometry and Visual Science Programme

School of Healthcare Sciences

Faculty of Health Sciences

Universiti Kebangsaan Malaysia

Jalan Raja Muda Abdul Aziz

50300 UKM Kuala Lumpur, Federal Territory

Malaysia

Noorhazayti Ab. Halim

Department of Paediatric Dentistry and Dental Public Health

Kulliyyah of Dentistry

International Islamic University Malaysia

Bandar Indera Mahkota

25200 Kuantan, Pahang Darul Makmur

Malaysia

*Corresponding author; email: syah@iium.edu.my

Received: 8 October 2019

Accepted: 2 February 2020 